\title{
In Situ Energy Dispersive X-Ray Diffraction Analysis of the Temperature-Pressure Stability of $\mathrm{Co}-\mathrm{Fe}-(\mathrm{Ta}, \mathrm{W})-\mathrm{B}$ Alloys
}

\author{
R. KAnÁSZ ${ }^{a}$, J. BednARČÍK ${ }^{b, *}, \mathrm{~K} . \mathrm{SAKSL}^{b, c}, \mathrm{R} . \mathrm{NiCUlA}^{d}$, \\ M. STIR ${ }^{d}$ AND C. LATHE
}

${ }^{a}$ Institute of Physics, Faculty of Science, P.J. Šafárik University

Park Angelinum 9, 04154 Košice, Slovak Republic

${ }^{b}$ Deutsches Elektronen Synchrotron (HASYLAB)

Notkestraße 85, 22607 Hamburg, Germany

${ }^{c}$ Institute of Materials Research, Slovak Academy of Sciences

Watsonova 47, 04353 Košice, Slovak Republic

${ }^{d}$ University of Rostock, Institute of Physics

August-Bebel-Str. 55, 18055 Rostock, Germany

${ }^{e}$ GeoForschungsZentrum Potsdam at DESY/HASYLAB

In this work two $\mathrm{Co}_{53.5} \mathrm{Fe}_{10} \mathrm{X}_{5.5} \mathrm{~B}_{31}(\mathrm{X}=\mathrm{Ta}, \mathrm{W})$ alloys were synthesized from high purity $(\geq 99.9 \%)$ powder elements by means of mechanical alloying. In case of Ta-addition, mechanical alloying resulted in formation of two component material with nanocrystalline phase embedded in amorphous matrix. On the other hand, substitution of Ta by $\mathrm{W}$ retards partial amorphization induced by mechanical alloying. High pressure-temperature stability of both alloys was monitored using in situ energy dispersive X-rays.

PACS numbers: $61.10 . \mathrm{Nz}, 75.50 . \mathrm{Kj}$

\section{Introduction}

It was recently reported that amorphous $\mathrm{Co}-\mathrm{Fe}-\mathrm{Ta}-\mathrm{B}$ alloys combine the ultrahigh mechanical strength [1] with the excellent soft magnetic properties [2] and thus appear as promising engineering materials. However, limited glass forming ability restricts their macroscopic dimensions. Alternatively, Co-rich soft magnetic

*corresponding author; e-mail: jozef.bednarcik@desy.de 
glasses can be prepared in bulk form by hot powder compaction [3]. The main aim of this work is to synthesize $\mathrm{Co}-\mathrm{Fe}-(\mathrm{Ta}, \mathrm{W})-\mathrm{B}$ alloys in the amorphous state by mechanical alloying (MA). Special emphasis is placed at the investigation of their high pressure-temperature stability by in situ energy-dispersive X-rays (EDX).

\section{Experimental}

Co-rich alloys with nominal composition $\mathrm{Co}_{53.5} \mathrm{Fe}_{10} \mathrm{X}_{5.5} \mathrm{~B}_{31}(\mathrm{X}=\mathrm{Ta}, \mathrm{W})$ were synthesized from high-purity powders $(\geq 99.9 \%)$ by means of MA using a RETSCH PM400 planetary ball mill. The MA was performed with hardened steel vials and balls at a ball-to-powder mass ratio of 14:1 with a speed of $200 \mathrm{rpm}$ for 25 hours. High-energy X-ray diffraction (XRD) measurements were performed at the undulator beamline PETRA 2 of HASYLAB (Hamburg, Germany) using monochromatic synchrotron radiation of $112 \mathrm{keV}(\lambda=0.110696 \AA)$. The samples measured at room temperature were illuminated for $30-60 \mathrm{~s}$ by well collimated incident beam having cross-section of $1 \times 1 \mathrm{~mm}^{2}$. In situ EDX experiments were done at the F2.1 beamline of HASYLAB. Details on the high-pressure equipment and typical experimental procedures can be found in Ref. [4]. The applied pressure was calibrated using the Decker $\mathrm{NaCl}$ equation of state [5]. The series of EDX spectra were acquired during continuous specimen heating (up to $1000^{\circ} \mathrm{C}$ ) without and with applying an external pressure.

\section{Results and discussion}

From Fig. 1a it is evident that Ta-containing sample exhibits rather diffuse XRD pattern, similar to that of amorphous alloys. However, the appearance of additional relatively weak and broad Debye-Scherrer rings indicates that MA does not result in formation of fully amorphous material. As can be seen from Fig. 1b the radial integration of two-dimensional XRD patterns results in low-noise data which allow phase identification. The structure of Ta-containing alloy consists of
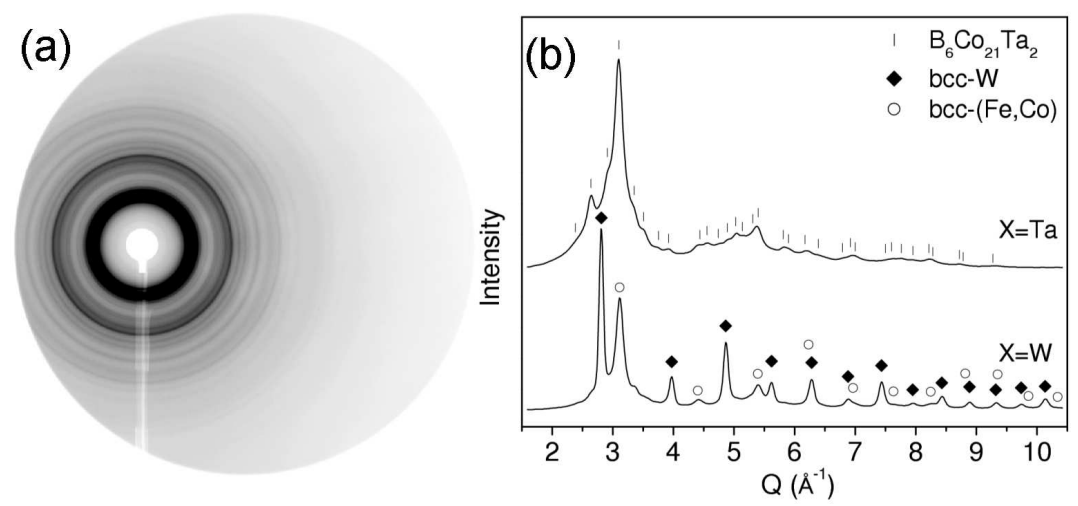

Fig. 1. (a) The two-dimensional XRD pattern of Ta-containing sample. (b) Radially integrated XRD patterns of $\mathrm{Co}_{53.5} \mathrm{Fe}_{10} \mathrm{X}_{5.5} \mathrm{~B}_{31}(\mathrm{X}=\mathrm{Ta}, \mathrm{W})$ alloys milled for $25 \mathrm{~h}$. 
amorphous and cubic $\mathrm{B}_{6} \mathrm{Co}_{21} \mathrm{Ta}_{2}$ (space group (S.G.)225, $a=10.54 \AA$ ) phases. On the other hand, XRD pattern of W-containing sample exhibits well defined but still relatively broad peaks which could be assigned to bcc-W (S.G. $229, a=3.1648 \AA$ ) and bcc-(Fe,Co) (S.G. 221, $a=2.85 \AA$ ) phases. Furthermore, it reveals rather weak traces of cubic $\mathrm{B}_{6} \mathrm{Co}_{21} \mathrm{~W}_{2}$ phase (S.G. 225).

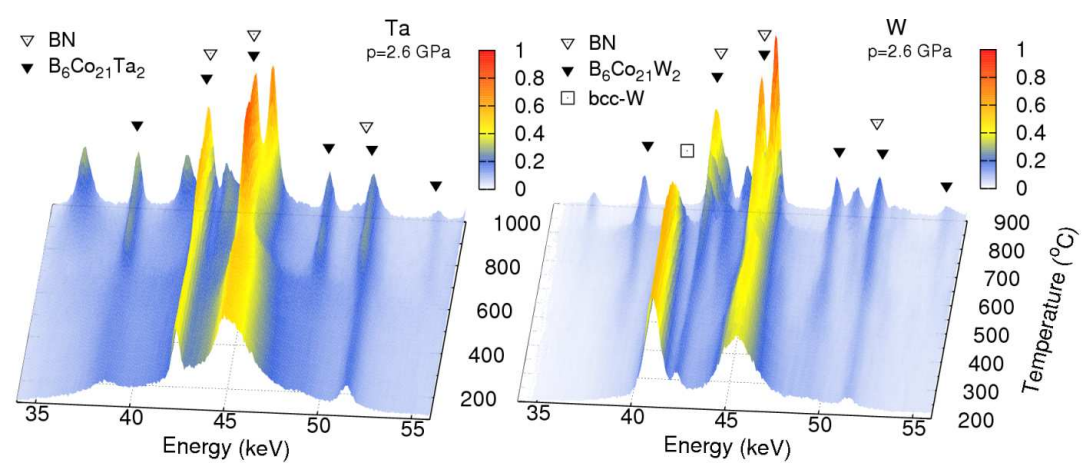

Fig. 2. In situ EDX spectra of $\mathrm{Co}_{53.5} \mathrm{Fe}_{10} \mathrm{X}_{5.5} \mathrm{~B}_{31}(\mathrm{X}=\mathrm{Ta}, \mathrm{W})$ alloys upon heating under applied constant pressure of $2.6 \mathrm{GPa}$. $E d=92.1846 \mathrm{keV} \AA$.

Figure 2 shows two series of EDX spectra corresponding to Ta- and $\mathrm{W}$-containing samples acquired under applied pressure of 2.6 GPa. From the in situ EDX spectra it follows that the structure of both alloys is preserved up to $525^{\circ} \mathrm{C}$. In the temperature range between 550 and $580^{\circ} \mathrm{C}$ the main constituent phases $\mathrm{B}_{6} \mathrm{Co}_{21} \mathrm{Ta}_{2}$ and $\mathrm{B}_{6} \mathrm{Co}_{21} \mathrm{~W}_{2}$ starts to progressively develop. In case of $\mathrm{W}$ containing sample initial phases bcc- $(\mathrm{Fe}, \mathrm{Co})$ and bcc-W disappear from the EDX spectra at $550^{\circ} \mathrm{C}$ and $800^{\circ} \mathrm{C}$, respectively. Above $800^{\circ} \mathrm{C}$ both alloys exhibit traces of yet unidentified phases. Under applied pressure (2.6 GPa) the phase constitution of the final products for both alloys remains unchanged.

The evolution of the unit cell parameter, $a$, with the applied temperature, $T$, and pressure, $P$, is plotted in Fig. 3. Such $a=a(T, P)$ dependences were inferred from the series of EDX spectra by fitting the position of reflections (420) and (440) belonging to $\mathrm{B}_{6} \mathrm{Co}_{21} \mathrm{Ta}_{2}$ and $\mathrm{B}_{6} \mathrm{Co}_{21} \mathrm{~W}_{2}$ cubic phases. The stronger reflections (422) and (511) could not be used due to overlap with reflections coming from BN (sample container). As can be seen from Fig. 3, applied pressure of 2.6 GPa shifts $a=a(T, P)$ toward lower values. A change in the thermal expansion behaviour under applied pressure is seen for both samples between $700-800^{\circ} \mathrm{C}$. This correlates with the nucleation of additional (yet unidentified) phases in this temperature range and suggests the lowering of nucleation barriers under pressure, more pronounced for the $\mathrm{W}$-containing alloy. 


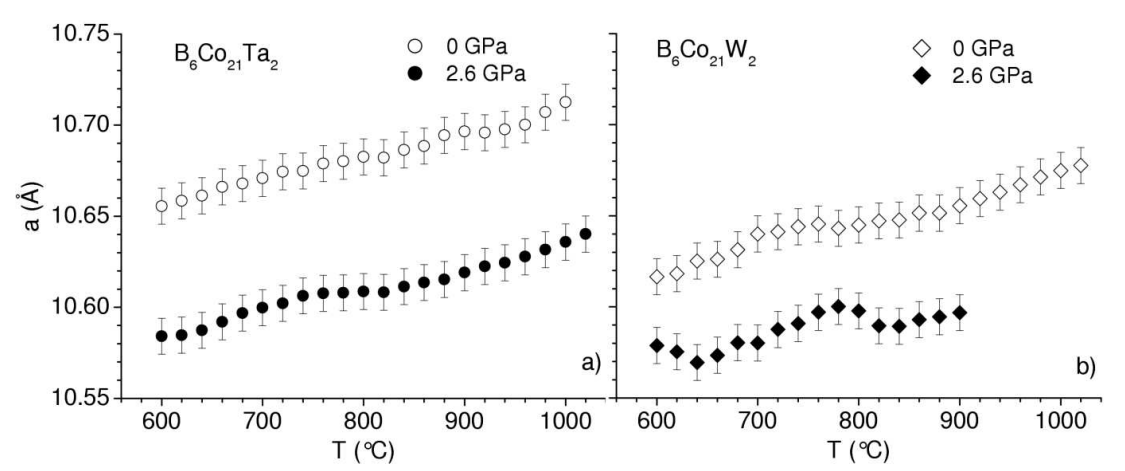

Fig. 3. The temperature-pressure dependences of the unit cell parameter, $a$, corresponding to (a) $\mathrm{B}_{6} \mathrm{Co}_{21} \mathrm{Ta}_{2}$ and (b) $\mathrm{B}_{6} \mathrm{Co}_{21} \mathrm{~W}_{2}$ cubic phases.

\section{Conclusions}

MA of $\mathrm{Co}-\mathrm{Fe}-\mathrm{Ta}-\mathrm{B}$ resulted in formation of two-component material with nanocrystalline $\mathrm{B}_{6} \mathrm{Co}_{21} \mathrm{Ta}_{2}$ phase embedded in amorphous matrix. On the other hand, substitution of Ta by $\mathrm{W}$ retards partial amorphization induced by MA. The observation of temperature-pressure stability of mechanically alloyed samples by high-temperature in situ EDX experiments showed that applying pressure of 2.6 GPa does not change the nature of phase transformations involved, however pressure seems to support the nucleation of high-temperature phases in both alloys.

\section{Acknowledgments}

R.K. acknowledges the support from DESY-D-II-20060031 through the E.U. project RII3-CT-2004-506008 (IA-SFS). K.S. is indebted to the Slovak Grant Agency for Science for financial support (grant No. 2/7196/27).

\section{References}

[1] A. Inoue, B. Shen, H. Koshiba, H. Kato, A.R. Yavari, Nature Mater. 2, 661 (2003).

[2] A. Inoue, B.L. Shen, H. Koshiba, H. Kato, A.R. Yavari, Acta Mater. 52, 1631 (2004).

[3] J. Bednarčík, P. Kollár, S. Roth, J. Eckert, Phys. Status Solidi A 199, 299 (2003).

[4] M. Stir, R. Nicula, E. Burkel, J. Eur. Ceram. Soc. 26, 1547 (2006).

[5] D.L. Decker, J. Appl. Phys. 42, 3239 (1971). 